\title{
Correction to: Apoptosis resistance in epithelial tumors is mediated by tumor-cell-derived interleukin-4
}

\author{
M. Todaro ${ }^{1}$ Y. Lombardo ${ }^{1} \cdot$ M. G. Francipane ${ }^{1} \cdot$ M. Perez Alea $^{1} \cdot$ P. Cammareri ${ }^{2} \cdot$ F. lovino ${ }^{1}$ A. B. Di Stefano ${ }^{1}$. \\ C. Di Bernardo ${ }^{2}$ A. Agrusa ${ }^{2}$ - G. Condorelli ${ }^{3} \cdot$ H. Walczak ${ }^{4} \cdot$ G. Stassi ${ }^{1}$
}

Published online: 8 August 2019

(c) The Author(s), under exclusive licence to ADMC Associazione Differenziamento e Morte Cellulare 2019

\section{Correction to: Cell Death \& Disease}

https://doi.org/10.1038/sj.cdd.4402305

published online 18 January 2018
We have only now noticed that in Fig. 3a, the immunohistochemical analysis of IL-4R $\alpha$ on paraffin-embedded sections from breast is incorrect: IL-4 from breast was duplicated and used for the IL-4R $\alpha$ staining. The correct Fig. $3 \mathrm{a}$ is given below.
These authors contributed equally: M. Todaro, Y. Lombardo

The original article can be found online at https://doi.org/10.1038/sj. cdd.4402305.

H. Walczak

h.walczak@dkfz.de

$\bowtie$ G. Stassi

gstassi@tiscali.it

1 Department of Surgical and Oncological Sciences, University of Palermo, Palermo, Italy

2 Department of Genurto, University of Palermo, Palermo, Italy

3 Department of Cellular and Molecular Biology and Pathology, University of Naples 'Federico II', Naples, Italy

4 Division of Apoptosis Regulation, German Cancer Research Center (DKFZ), Heidelberg, Germany 
a

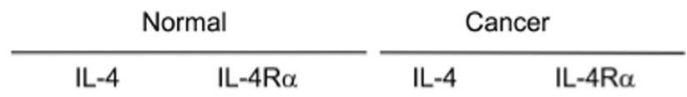

Colon
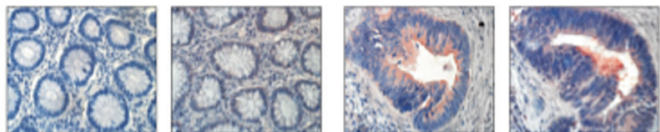

Breast

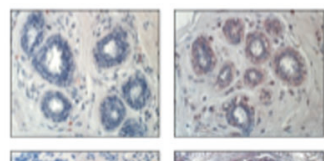

Lung
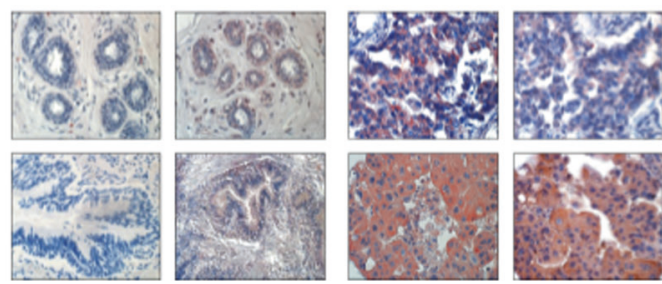

Fig. 3 